\title{
A Educação Ambiental como Objeto de Estudos nos Programas Stricto Sensu em Turismo no Brasil (período 1997 - 2011)
}

\author{
Environmental Education as an Object of Study in Post-graduate \\ Programmes in Tourism in Brazil (period 1997-2011)
}

\section{La educación ambiental como objeto de estudio en programas de postgrado en Turismo en Brasil (período 1997-2011)}

\section{Maria Salete Goulart Martins Denicol ${ }^{1}$ Suzana Maria De Conto ${ }^{2}$}

\begin{abstract}
Resumo: A Educação Ambiental (EA) é uma importante ferramenta para o desenvolvimento do turismo sustentável, sendo utilizada na sensibilização das pessoas sobre a minimização dos impactos ambientais, decorrentes do uso de recursos naturais nas atividades turísticas. Nessa perspectiva, estudos sobre a EA nos Programas de Pós-Graduação Stricto Sensu em Turismo, no Brasil, parecem ser importantes e necessários para identificar tendências e lacunas no processo de produção de conhecimento. $O$ objetivo de estudo é mapear como a Educação Ambiental é contemplada na produção do conhecimento nas dissertações desses Programas, reconhecidos e recomendados pela Capes no período de 1997 a 2011 . A pesquisa é de caráter descritivo e analisa as dissertações (que contemplam na investigação a Educação Ambiental), constantes no Banco de Teses da Capes. Os resultados obtidos permitem concluir que, dos seis Programas de Pós-Graduação Stricto Sensu em Turismo no Brasil, apenas cinco dissertações (duas do Programa de Mestrado em Turismo e Hotelaria, da Universidade do Vale do Itajaí e três do Programa de Mestrado em Turismo da Universidade de Caxias do Sul) contemplam a educação ambiental como objeto de estudo.
\end{abstract}

Palavras-chave: Turismo; Educação Ambiental; Programas Stricto Sensu em Turismo; Pesquisas em Educação Ambiental.

Abstract: Environmental Education (EE) is an important tool for the sustainable development of tourism, which is used to educate people on minimizing environmental impacts caused by the use of natural resources in tourist activities. Within this perspective, studies on EA in the Post-graduate Programmes in tourism in Brazil seem to be important and necessary to identify trends and gaps in the process of

1 Graduada em Ciências Econômicas pela Universidade de Caxias do Sul (UCS). Especialista em Contabilidade pela (UCS). Especialista em Gestão Empresarial pela Universidade Federal do Rio Grande do Sul (UFRGS). Mestre em Turismo na Universidade de Caxias do SUL. Docente no Centro de Economia, Contabilidade e Comércio Internacional na mesma universidade.E-mail: msdenicol@gmail.com

2 Engenheira Química pela UCS e Doutora em Educação pela UFSCar. Docente no Centro de Ciências Exatas e Tecnologia, no Mestrado em Turismo e no Mestrado Profissional em Engenharia e Ciências Ambientais da UCS. Líder do Grupo de Pesquisa “Gestão Ambiental no Turismo". E-mail: smcmande@ucs.br. 
knowledge production. The aim of this study is to map how Environmental Education is contemplated in knowledge production in the dissertations of those programmes, which are recommended by Capes from 1997 a 2011. This research is exploratory and analyses dissertations which look at environmental education from Capes Theses Repository. The results show that from six Post-Graduate Programmes in Tourism in Brazil, only five dissertations (two from the Master Programme in Tourism and Hospitality of Universidade do Vale do Itajaí and three from the Master Programme in Tourism of Universidade de Caxias do Sul) contemplate environmental education as an object of study.

Keywords: Tourism; Environmental Education; Post-graduate Programmes in Tourism; Research on Environmental Education

Resumen: La Educación Ambiental (EA) es una herramienta importante para el desarrollo del turismo sostenible, que se utiliza en la educación de las personas hacia la disminución de los impactos ambientales, como consecuencia del uso de recursos naturales en las actividades turísticas. En ese sentido, investigaciones sobre la EA en los programas de postgrado Stricto Sensu en Turismo, en Brasil, parecen ser importantes y necesarios para identificar propensiones y huecos en el proceso de producción del conocimiento. El objetivo de este estudio es identificar cómo la Educación Ambiental aparece en la producción de conocimiento en las tesinas de esos Programas, reconocidos y recomendados por la Capes durante el período de 1997 hasta 2011. La investigación es de carácter descriptivo y analiza las tesinas (cuya temática es la educación ambiental), que están disponibles en el Banco de Tesinas de la Capes. Los resultados permiten concluir que, de los seis programas de postgrado Stricto Sensu en Turismo en Brasil, solo cinco tesinas (dos del Programa de Maestría en Turismo y Hostelería, de la Universidad del Vale do Itajaí y tres del programa de Maestría en Turismo de la Universidad de Caxias do Sul) contemplan la educación ambiental como objeto de investigación.

Palabras-claves: Turismo; Educación Ambiental;Postgrado Stricto Sensu en Turismo; Investigación en Educación Ambiental.

\section{INTRODUÇÃO}

A partir da análise de como a Educação Ambiental vem sendo contemplada nos diferentes setores da sociedade, surgem questões que parecem exigir estudos e respostas com certa profundidade e que auxiliem no entendimento do papel essencial da Educação Ambiental no contexto atual.

A Educação Ambiental é entendida como uma necessidade formativa permanente de todos os cidadãos, cabendo a todos os setores da sociedade, às instituições de ensino, à iniciativa privada e ao Poder Público propor ações e políticas que contemplem a mesma no seu planejamento e na sua gestão. Analisando a Política Nacional de Educação Ambiental - Lei 9.795, de 27 de abril de 1999 (Brasil, 1999), fica evidente o papel das Instituições de Ensino Superior (IES) no cumprimento do que estabelece a referida Lei. Em seu art. 2º, a política nacional de Educação Ambiental evidencia:

A educação ambiental é um componente essencial e permanente da educação nacional, devendo estar presente, de forma articulada, em todos os níveis e modalidades do processo educativo, em caráter formal e não formal. (Brasil, 1999). 
A educação para o turismo, segundo Ruschmann (2001), envolve necessariamente a Educação Ambiental, devendo ser desenvolvida por meio de programas não formais, que conscientizem o turista sobre a proteção ao meio ambiente, não apenas no momento da viagem, mas também em seu local de residência permanente.

Botelho (2007), ao pesquisar a Educação Ambiental no turismo, menciona que seria uma viagem turística diferenciada, uma outra viagem turística, mais humana, mais rica em experiência e comprometida com a construção do ser humano. O mesmo autor complementa:

Neste transitar por outras experiências, proporcionadas pela educação ambiental nas viagens turísticas, estaremos contribuindo para outro olhar, Isto é, construindo instrumentos para os viajantes reinventarem o observar: ao encarar aos outros, definirem valores e tomarem atitudes para um melhor caminho em suas vidas. (Botelho, 2007, p. 126).

Desta maneira, torna-se primordial a inserção da Educação Ambiental na área do turismo, que é essencialmente uma atividade de ocupação de espaços, lugares, regiões, paisagens, e deve ter como preocupação a responsabilidade no uso dos recursos naturais dos locais visitados.

Considerando que a Educação Ambiental, de acordo com as diretrizes legais nacionais, estaduais e municipais, deve ser desenvolvida nos diferentes setores da sociedade de forma contínua e permanente, derivam-se questionamentos no presente estudo: a) A dimensão ambiental é contemplada nas linhas de pesquisas dos cursos de mestrado e doutorado em Turismo no Brasil?; b) Como ocorre a relação entre Turismo e Educação Ambiental nos cursos de Pós-Graduação Stricto Sensu em Turismo no Brasil?; c) O que vem sendo estudado sobre o tema nos Programas Stricto Sensu em Turismo recomendados pela Capes?; d) Quais são as tendências na produção de conhecimento sobre esse tema?; e) Quais as regiões do País em que a temática vem sendo pesquisada com maior frequência nesses Programas?; f) Quais são os eixos temáticos mais estudados sobre a Educação Ambiental nos Programas Stricto Sensu em Turismo no Brasil?

Essas perguntas merecem ser analisadas e respondidas, no sentido de identificar as tendências e as possíveis lacunas na produção desse tema, incentivando a reflexão e produção de novos saberes sobre Educação Ambiental, nos Programas Stricto Sensu em Turismo, no Brasil. A partir dessas indagações, surge a seguinte pergunta de pesquisa: Como o tema Educação Ambiental vem sendo estudado nas dissertações dos Programas Stricto Sensu em Turismo, no Brasil?

A pesquisa, desenvolvida por Denicol (2013) durante o Mestrado em Turismo, buscou identificar com maior clareza o que constitui as bases conceituais da Educação Ambiental, em quais Instituições de Ensino Superior - Programas Stricto Sensu em Turismo - vem sendo produzido conhecimento que tenha como objeto de estudo a Educação Ambiental (período 1997 a 2011). O objetivo geral desta pesquisa é mapear como a Educação Ambiental é contemplada na 
produção do conhecimento nas dissertações dos Programas Stricto Sensu em Turismo recomendados pela Coordenação de Aperfeiçoamento de Pessoal de Nível Superior (Capes).

As reflexões propostas por esta pesquisa evidenciam a importância de as instituições de ensino superior cumprirem a sua função: fomentar a produção e socialização do conhecimento em todas as áreas integrando Educação Ambiental. Os resultados do estudo dessas questões parecem servir como instrumento para que as Instituições de Ensino Superior, nos cursos de Pós-Graduação Stricto Sensu em Turismo, no Brasil, caso não tenham linhas de pesquisa ou disciplinas em Educação Ambiental, planejem a implementação das mesmas.

\section{BASES CONCEITUAIS DA EDUCAÇÃO AMBIENTAL}

É importante destacar a Lei 9.795, de 27 de abril de 1999, que dispõe sobre a Educação Ambiental e que institui a Política Nacional de Educação Ambiental, no sentido de definir diretrizes relacionadas à concepção e operacionalização da Educação Ambiental em espaços formais e não formais, aproximando-a de conceitos como democratização, cidadania e igualdade. (Brasil, 1999). Conforme é definido no art. 1ㅇ dessa lei, a Educação Ambiental é entendida como:

Os processos por meio dos quais o indivíduo e a coletividade constroem valores sociais, conhecimentos, habilidades, atitudes e competências voltadas para a conservação do meio ambiente, bem de uso comum do povo, essencial à sadia qualidade de vida e sua sustentabilidade. (Brasil, 1999).

Essa Política também destaca, em seu art. 5o os objetivos fundamentais da Educação Ambiental:

I - o desenvolvimento de uma compreensão integrada do meio ambiente em suas múltiplas e complexas relações, envolvendo aspectos ecológicos, psicológicos, legais, políticos, sociais, econômicos, científicos, culturais e éticos;

II - a garantia de democratização das informações ambientais;

III - o estímulo e o fortalecimento de uma consciência crítica sobre a problemática ambiental e social;

IV - o incentivo à participação individual e coletiva, permanente e responsável, na preservação do equilíbrio do meio ambiente, entendendo-se a defesa da qualidade ambiental como um valor inseparável do exercício da cidadania;

V - o estímulo à cooperação entre as diversas regiões do País, em níveis micro e macrorregionais, com vistas à construção de uma sociedade ambientalmente equilibrada, fundada nos princípios da liberdade, igualdade, solidariedade, democracia, justiça social, responsabilidade e sustentabilidade;

$\mathrm{VI}$ - o fomento e o fortalecimento da integração com a ciência e a tecnologia;

VII - o fortalecimento da cidadania, autodeterminação dos povos e solidariedade como fundamentos para o futuro da humanidade. (Brasil, 1999).

As atividades vinculadas à Política Nacional de Educação Ambiental, conforme o que determina 0 art. 8ㅇ da referida Lei, devem ser desenvolvidas na educação em geral e na educação 
escolar, por meio da capacitação de recursos humanos, sendo que esta deverá incorporar a dimensão ambiental na formação, especialização e atualização dos educadores de todos os níveis e modalidades de ensino. (Brasil, 1999).

A Educação Ambiental tem uma influência significativa sobre a consciência ambiental, a vida cotidiana e o comportamento do consumidor (Zsóka et al., 2013). Os autores destacam que várias instituições de Ensino Superior, na Hungria, reconhecem a importância de integrar as questões de sustentabilidade na educação.

No Brasil, no processo de avaliação dos cursos de graduação e a distância (INEP, 2012), o requisito legal e normativo de número 13 (instrumento de avaliação) está relacionado à Política Nacional de Educação Ambiental. Com base nesse requisito, os cursos precisam demonstrar a integração da Educação Ambiental às disciplinas dos mesmos, de modo transversal, contínuo e permanente. (INEP, 2012). Cabe destacar que a Política Nacional de Educação Ambiental declara que a Educação Ambiental não deve ser implantada como disciplina específica no currículo de ensino. Porém, nos cursos de pós-graduação, extensão e nas áreas voltadas ao aspecto metodológico da Educação Ambiental, quando se fizer necessário, é facultada a criação de disciplina específica (Brasil, 1999).

Sauvé (2008) apresenta uma cartografia das correntes em educação ambiental, escrevendo que, ao abordar o campo da Educação Ambiental, é possível perceber que, apesar de a preocupação ser com o meio ambiente e com o papel central da educação, para melhorar este meio ambiente, diferentes autores (pesquisadores, professores, entre outros) adotam diferentes falas sobre educação ambiental, e os mesmos propõem várias maneiras de conceber e praticar ações educativas.

As publicações em Educação Ambiental e titulação acadêmica, para a formação de profissionais em lato ou stricto sensu (cursos de especialização, mestrados e doutorados), tiveram seu crescimento na década de 90 . Motivado pela globalização mundial, este contexto nacional segue o cenário internacional. (Sato \& Santos, 2003). De acordo com os autores a Educação Ambiental

exige um debate sobre suas bases de sustentação, obviamente com aberturas epistemológicas que confiram seu alto poder de diversidade e interfaces que a sua própria natureza requer. Pensando isso, acreditamos que discutir caminhos da pesquisa talvez seja uma forma interessante de corroborar com a (re)construção da EA. Consideramos que essa foi uma das mais importantes trilhas que conduziram ao atual pensamento da $E A$, em constante movimento dinâmico. E por isso mesmo, reconhecemos os avanços e os recuos deste movimento, ora em círculo fechado, ora aberto, possibilitando enveredar por caminhos desconhecidos, descobrindo, assim, novas formas do pensar e do agir, inseridos em contextos plurais, onde a diversidade possibilita e garante a riqueza da descoberta da própria EA. (Sato \& Santos, 2003, p. 250). 
Souza e Salvi (2012) reiteram a importância das investigações em EA, principalmente as que são desenvolvidas nos Programas de Pós-Graduação nos quais, atualmente, vem se constatando um aumento na produção acadêmica e científica na área.

Para Sato e Santos (2003), a pesquisa é uma indagação que orientada conduz a uma permanente inquietação na busca do conhecimento, através da observação, em que as nossas atitudes refletem a realidade e as mudanças que desejamos, seja em espaço escolar, seja no universitário. Os autores complementam:

Sabemos que não mudaremos a sociedade inteira, reconhecemos a limitação da educação. Entretanto é na potencialidade da educação que queremos ancorar nossos pensamentos, abrindo janelas para um horizonte mais próximo, buscando uma utopia que teremos a coragem de realizar. (Sato \& Santos, 2003, p. 251).

Tomazello (2005), em estudo que apresenta "Reflexões Acerca das Dissertações e Teses Brasileiras em Educação Ambiental do Período de 1987-2001", destaca que apesar de já se passarem mais de 28 anos da Conferência de Tbilisi, no Brasil, nos últimos anos, é que a Educação Ambiental passou a ter importância na sociedade. Em diferentes espaços científicos, muitas investigações estão sendo conduzidas. A pesquisa teve como objetivo fazer uma análise das dissertações e teses brasileiras, catalogadas no Banco de Teses da Capes, no período de 1987 a 2001. A autora conclui que "é notória a falta de linhas de pesquisa nos programas de PósGraduação, em especial na área de Educação". (Tomazello, 2005, p. 5).

De acordo com Lorenzetti e Delizoicov (2007), observa-se um aumento significativo no número de programas de pós-graduação nacional, na produção da pesquisa de campo em Educação Ambiental, trazendo contribuições ao processo de formação do pesquisador em Educação Ambiental.

Também Carvalho, Tomazello e Oliveira (2009) complementam, afirmando a evidência do aumento de trabalhos produzidos em educação ambiental nos programas de Pós-Graduação nos últimos anos. Os mesmos evidenciam como tendência ser dentro do sistema público universitário o local privilegiado desta produção científica e afirmam a existência de concentração de trabalhos em determinadas regiões do Brasil.

Importantes contribuições são apresentadas por Souza (2010), em sua dissertação, que faz um mapeamento das dissertações e teses produzidas nas pós-graduações stricto sensu brasileiras, no período de 2003 a 2007, com o título: “Cartografia da Educação Ambiental nas pós-graduações stricto sensu brasileiras (2003-2007): ênfase na pesquisa de educação e de ensino nas ciências sobre formação de professores". Em sua pesquisa, Souza (2010) teve como objetivo levantar as dissertações e teses produzidas nas pós-graduações stricto sensu, reconhecidas e recomendadas pela Capes, visando a um aprofundamento sobre os objetivos e as temáticas dos trabalhos das áreas de Educação e de Ensino de Ciências e Matemática, que abordam a formação de professores/educadores. A autora utilizou a metodologia do tipo "estado da arte", destacando que estudos dessa natureza, sobre a pesquisa em Educação Ambiental, estão sendo desenvolvidos 
para analisar as temáticas e a qualidade das pesquisas de pós-graduações, com a intenção de contribuir para a consolidação do campo e indicar suas tendências e lacunas.

Ainda Souza (2010) destaca que houve um crescimento substancial nos últimos cinco anos, em nível nacional, na produção de dissertações e teses sobre a temática Educação Ambiental, nas mais diversas áreas do conhecimento e, consequentemente, em diversos programas de pósgraduação. Os principais resultados desse estudo destacam que, dos 847 trabalhos do período analisado (2003-2007), a maior produção ficou com a área de Educação (43,68\%), seguida pelos cursos da área interdisciplinar (19,36\%), Ensino de Ciências e Matemática (8,15\%), Geografia (5,19\%), Engenharia Sanitária (4,37\%), Ecologia (3,9\%) e as demais áreas do conhecimento com menos de (2\%) do total de cada uma. São elas: Administração, Agronomia, Antropologia, Arquitetura e Urbanismos, Bioquímica, Biotecnologia, Botânica, Biologia, Ciência da Informação, Comunicação, Direito, Economia, Educação Física, Enfermagem, Engenharia Agrícola, Engenharia Civil, Engenharia da Produção, Engenharia de Materiais e Metalurgia, Engenharia Mecânica, Engenharia Química, Filosofia (Filosofia/Teologia), Geociências, História, Planejamento Urbano e Regional, Psicologia, Recursos Florestais e Engenharia Florestal, Saúde Coletiva, Serviço Social, Turismo e Letras. Cabe destacar que a área do Turismo aparece com apenas duas dissertações, sendo uma no ano de 2004 e outra em 2006.

\section{A EDUCAÇÃO AMBIENTAL NO TURISMO}

No que tange ao turismo, Souza (2010) destaca, a partir dos resultados de sua investigação, que existem 38 áreas de conhecimento, onde foi constatado, como foco de interesse de investigação, a Educação Ambiental, sendo que a área do turismo se encontra em 370. Com esses resultados, evidencia-se a escassez de pesquisas sobre EA no turismo e a necessidade de um maior aprofundamento em seus programas stricto sensu no Brasil. A autora destaca que a inserção do tema é considerada um avanço e reflexo da busca pela legitimação da Educação Ambiental nos diferentes campos do saber e expressa o amadurecimento e a consolidação dessa área de conhecimento no Brasil.

Nos estudos realizados por Weiler, Moyle e McLennan (2012), identifica-se que as pesquisas de doutorado, com foco no turismo, entre os anos de 1951 a 2010, têm crescido de forma exponencial. Esse estudo segue a mesma linha de pesquisa anteriormente realizada em: Canadá, Austrália, Estados Unidos e Nova Zelândia. Baseiam-se ainda nos estudos de Jafari e Aaser (1988), no período de 1951 a 1987; nos de Hall e Pedrazinni (1989), no período de 1979 a 1988 e por último Meyer-Arendt e Justice (2002) no período de 1987 a 2000. Nas conclusões dos autores é destacado que as pesquisas de doutorado em turismo apresentam indicadores de crescimento e de maturidade teórica sobre o tema.

Os autores, ao avaliarem as produções nos quatro países, encontraram diferentes assuntos abordados nas pesquisas, concluindo ser a área do turismo multidisciplinar. Das 1.888 "dissertações de doutorado", compiladas na pesquisa, 63\% eram americanas, 24\% australianas, 
$7 \%$ canadenses e $6 \%$ neozolandesas. As áreas em destaque pelas produções, nos quatro países estudados, foram: psicologia (289 teses); educação ambiental (270 teses) e antropologia (239 teses). Os autores complementam que a produção científica em Educação Ambiental apresenta maior número de trabalhos desenvolvidos nas instituições que incentivam e oferecem disciplinas nessa área.

Weiler, Moyle e McLennan (2012) constataram em sua pesquisa que, na Austrália, os estudos em Educação ambiental cresceram em um avanço de seis dissertações por ano de 2000 a 2009, chegando a 80 dissertações, se comparados à produção de uma dissertação ao ano antes desse período.

Ao analisar a Educação Ambiental como objeto de estudo no Seminário de Pesquisa em Turismo do Mercosul (SeminTur), no período de 2003 a 2010, Denicol, De Conto e Kunz (2012) identificaram que $2,8 \%$ do total dos 748 artigos analisados contemplavam, como objeto de estudo, a Educação Ambiental. Os autores destacam que existe uma lacuna no que diz respeito à produção de trabalhos acadêmicos sobre Educação Ambiental e concluem no sentido de que ações devem ser planejadas e desenvolvidas nos eventos, para fomentar estudos pertinentes à temática.

Com contribuições nesse sentido, a pesquisa de Oliveira, Souza e Escobar (2012), ao analisarem a responsabilidade socioambiental nos periódicos científicos de turismo no Brasil, no período de 2001 a 2011, concluem que menos de 3\% do total analisado abordam questões específicas à responsabilidade socioambiental. Porém os mesmos ressaltam que é uma temática nova, que deve ser estimulada a analisar os impactos causados pelas atividades do turismo e estar presente na relação entre homem e natureza.

Nesse sentido, destaca-se que os cursos de pós-graduação stricto sensu em turismo assumem papel fundamental na formação de profissionais para atuarem na gestão das organizações turísticas, baseadas em uma visão mais sistêmica, nas quais a dimensão ambiental deve fazer parte do planejamento estratégico dessas organizações.

\section{METODOLOGIA}

Segundo a área de conhecimento, esta pesquisa classifica-se como sendo da área das Ciências Sociais Aplicadas, conforme classificação elaborada pelo Conselho Nacional de Desenvolvimento Científico e Tecnológico (CNPq), sendo esta a principal agência destinada ao fomento da pesquisa e formação de recursos humanos no Brasil. (Gil, 2010).

Esta pesquisa, de caráter descritivo e quanto aos procedimentos é bibliográfica, consiste na análise das dissertações defendidas nos programas de pós-graduação stricto sensu em turismo, recomendados pela Capes.

A pesquisa descritiva tem como objetivo principal a descrição das características de determinada população ou fenômeno, ou o estabelecimento de relações entre variáveis; prioriza, 
como característica significativa, a utilização de técnicas padronizadas de coleta de dados. (Gil, 2010).

O objetivo da pesquisa bibliográfica é o de conhecer e analisar as principais contribuições teóricas existentes sobre um determinado tema ou problema, fazendo com que a pesquisa bibliográfica seja um instrumento indispensável para qualquer tipo de pesquisa (Köche, 2009).

Importantes contribuições podem ser apontadas por Ferreira (2002) ao analisar a pesquisa do tipo "estado da arte", ou estado do conhecimento:

Nos últimos quinze anos tem se produzido um conjunto significativo de pesquisas conhecidas pela denominação "estado da arte" ou "estado do conhecimento". Definidas como de caráter bibliográfico, elas parecem trazer em comum o desafio de mapear e de discutir uma certa produção acadêmica em diferentes campos do conhecimento, tentando responder que aspectos e dimensões vêm sendo destacados e privilegiados em diferentes épocas e lugares, de que formas e em que condições têm sido produzidas certas dissertações de mestrado, teses de doutorado, publicações em periódicos e comunicações em anais de congressos e de seminários. Também são reconhecidas por realizarem uma metodologia de caráter inventariante e descritivo da produção acadêmica e científica sobre o tema que busca investigar, à luz de categorias e facetas que se caracterizam enquanto tais em cada trabalho e no conjunto deles, sob os quais o fenômeno passa a ser analisado. (Ferreira, 2002, p. 258).

Nessa direção, Souza e Salvi (2011) comentam que há uma crescente preocupação na realização de estudos do tipo "estado da arte", sobre a pesquisa em Educação Ambiental. Ainda, as autoras justificam que isso se deve à necessidade de aprofundamento e compreensão dos fundamentos dessa perspectiva de educação, assim como para o entendimento de sua institucionalização nacional.

Para Soares e Maciel (2000), ao comentar sobre a construção do conhecimento, justificam que as pesquisas de caráter bibliográfico, que têm como objetivo inventariar e sistematizar a produção em determinada área do conhecimento, normalmente são ditas pesquisas do "estado da arte".

Essa compreensão do "Estado do Conhecimento" sobre um tema em determinado momento é necessária no processo de evolução da ciência, a fim de que se ordene periodicamente conjunto de informações e resultados já obtidos, ordenação que permita a indicação das possibilidades de integração de diferentes perspectivas, aparentemente autônomas, a identificação de duplicações ou contradições e a determinação de lacunas ou vieses. (Soares \& Maciel, 2000, p. 9).

Oliveira e Resende (2010) identificam como tendência os estudos e as investigações do tipo "estado da arte" na última década, incluindo as pesquisas em Educação Ambiental. Mesmo recente, a produção acadêmica e científica nos programas stricto sensu no Brasil, envolvendo as pesquisas em Educação Ambiental, tem produzido mais e em diversificadas áreas e linhas de pesquisa. 


\subsection{Procedimentos de coleta e análise dos dados}

- procura no Banco de Teses da Capes das dissertações nos programas de pósgraduação stricto sensu em turismo em desenvolvimento no país, que apresentavam a expressão exata Educação Ambiental no título, palavras-chave e resumos (período de 1997 a 2011);

- leitura preliminar do material localizado e selecionado, como parte que compõe o corpus desta pesquisa;

- organização dos dados visando a mapear as informações pesquisadas no Banco de Teses da Capes no período compreendido de 1997 a 2011;

- análise e interpretação dos dados.

A data de encerramento da coleta de dados, no Banco de Teses da Capes, foi em 22 de janeiro de 2013. (CAPES, 2013a).

\subsection{Etapas de levantamento das produções na CAPES}

Como primeira etapa foi realizada a identificação dos Programas de Pós-Graduação Stricto Sensu que constam no Sistema da Capes. Na sequência buscaram-se os cursos recomendados por área de avaliação.

No quadro apresentado pela Capes para os cursos recomendados e reconhecidos por área de avaliação foi clicado na grande área "Ciências Sociais Aplicadas", em que se encontra a área do turismo (Administração, Ciências Contábeis e Turismo).

Na sequência, foram localizados os programas de pós-graduação stricto sensu de turismo em desenvolvimento no país. (Capes, 2012b).

Após identificados os seis programas, em IES existentes até a data de 31 de dezembro de 2011, foi feita busca nas fichas de avaliação de cada programa, no sentido de identificar a data de início dos mesmos.

Fazem parte destes programas (Capes, 2012b) o Mestrado em Turismo e Hotelaria da Universidade do Vale do Itajaí (Univali-SC), o Mestrado em Turismo da Universidade Caxias do Sul (UCS-RS); o Mestrado em Hospitalidade da Universidade Anhembi Morumbi (UAM-SP); o Mestrado em Turismo da Universidade de Brasília (UnB-DF); o Mestrado em Turismo da Universidade Federal do Rio Grande do Norte (UFRN-RN) e o Mestrado em Gestão de Negócios Turísticos na Universidade Estadual do Ceará (Uece-CE).

Após definidos os programas stricto sensu de turismo no Brasil, foram estabelecidos os critérios que constituíram o corpus para ser analisado nesta pesquisa. A pesquisa continuou utilizando, como fonte de dados, o endereço eletrônico da Capes, que disponibiliza a ferramenta de busca e consulta: a partir do link "Serviços", Banco de Teses da Capes, foi utilizada para a pesquisa a expressão exata Educação Ambiental no campo "Assunto". Após foi digitado o nome da IES, e escolhido o nível para a pesquisa (Doutorado/ Mestrado ou Mestrado Profissionalizante). 
Posteriormente, foi selecionado o período de busca (1997-2011), que foi definido em função do início dos programas na área de turismo em cada IES.

Para cada Resumo foi realizada a leitura das informações constantes na tela, no sentido de localizar a expressão exata Educação Ambiental (título, resumo e palavras-chave). Após, foi feita a busca do texto completo de todas as dissertações nas quais constava a expressão exata Educação Ambiental (no título, no resumo ou nas palavras-chave), em meio eletrônico dos programas de pós-graduação stricto sensu em turismo. Foram localizadas sete dissertações em meio eletrônico (site dos programas) e três em arquivo impresso, pois não se encontravam disponíveis em meio eletrônico no site dos programas. As dissertações impressas foram obtidas por meio de empréstimo entre instituições.

Com os textos completos, foi realizada a leitura buscando em que parte da estrutura do texto aparece a expressão exata Educação Ambiental e o número de ocorrências. Para localizar foi utilizada a ferramenta "abrir pesquisa total do reader".

Por meio da leitura dos trabalhos selecionados, foi localizado o objetivo geral, os objetivos específicos, o problema de pesquisa e os principais resultados.

\section{RESULTADOS}

Analisando os programas recomendados pela Capes na área do turismo no período de 1997 a 2011 (Capes, 2012a) destacam-se seis programas a saber: Mestrado em Turismo e Hotelaria da Universidade do Vale do Itajaí (Univali-SC), Mestrado em Turismo da Universidade Caxias do Sul (UCS-RS); Mestrado em Hospitalidade da Universidade Anhembi Morumbi (UAM-SP); Mestrado em Turismo da Universidade de Brasília (UnB-DF); Mestrado em Turismo da Universidade Federal do Rio Grande do Norte (UFRN-RN) e o Mestrado em Gestão de Negócios Turísticos na Universidade Estadual do Ceará (Uece-CE).

A partir da análise no Banco de Teses da Capes (2012a), identifica-se que apenas duas Instituições de Ensino Superior apresentam dissertações com a temática Educação Ambiental no turismo: Universidade do Vale do Itajaí e Universidade de Caxias do Sul. As mesmas apresentam dissertações (um total de cinco dissertações em cada um dos programas, representando 50\% em cada uma das instituições). Nos demais programas não foram localizados estudos sobre educação ambiental.

Também é possível observar que as orientações na Univali concentram-se em dois professores: Paulo dos Santos Pires com três dissertações identificadas com a expressão exata Educação Ambiental, no Banco de Teses da Capes e Marcus Polette com duas dissertações. Na Universidade de Caxias do Sul - UCS concentram-se em três professores: Suzana Maria De Conto com três dissertações identificadas com a expressão exata Educação Ambiental, no Banco de Teses da Capes; Rosane Maria Lanzer com uma dissertação e Edegar Luis Tomazzoni com uma dissertação.

Ao verificar as regiões em que os estudos foram desenvolvidos nas 10 dissertações localizadas com a expressão exata no Banco de Dados da Capes, identificou-se que a Região Sul 
apresenta-se como destaque, com estudos no Estado do Rio Grande do Sul, de Santa Catarina e do Paraná. Esta tendência pela Região Sul do País é evidenciada nos estudos de Carvalho, Tomazello e Oliveira (2009) e também em Souza (2010).

Analisando a ocorrência das categorias temáticas identificadas nos dez trabalhos estudados, destaca-se que dois trabalhos estão relacionados a parques (Santos, 2004; Watanabe, 2008); dois trabalhos a estudos de Ecoturismo (Bueno, 2006; Machado, 2011); dois trabalhos a meios de hospedagem (Silva, 2007; Zanette, 2010) e um trabalho na categoria comunicação (Corrêa, 2002), um na categoria observação de aves (Soares, 2002), um sobre estudo em terminal turístico em reservatório de hidrelétrica (Pertille, 2007) e um trabalho na categoria evento (Pereira, 2007).

Observa-se que as dissertações apresentadas no curso de Turismo da Universidade de Caxias do Sul destacam-se com as temáticas: meios de hospedagem, evento, ecoturismo/agências de turismo. Já as dissertações apresentadas no curso de Turismo e Hotelaria da Universidade do Vale do Itajaí destacam-se com temáticas envolvendo contemplação e observação do meio natural (parques, ecoturismo) e comunicação.

Apesar da ênfase dada nas 10 dissertações para a educação ambiental, constata-se que apenas cinco tinham como objeto de estudos a educação ambiental no turismo: Corrêa (2002) e Bueno (2006) da Univali e Pertille (2007), Pereira (2007) e Machado (2011) da UCS.

A primeira dissertação que versa sobre a temática trata-se dos estudos de Corrêa (2002), desenvolvida no Programa Stricto Sensu em Turismo e Hotelaria, da Universidade do Vale do Itajaí (Univali). Essa investigação teve como titulo "Proposta metodológica para comunicação em rádio Suporte para um turismo sustentável". Como objetivo principal desse estudo destaca-se a elaboração e aplicação de uma proposta metodológica, utilizando o rádio como meio de comunicação, de forma a verificar sua eficiência na difusão de conceitos de Educação Ambiental e na divulgação de informações sobre turismo e meio ambiente.

Corrêa (2002) destaca, a partir das respostas dos sujeitos da pesquisa, a importância do jornalismo como elemento "fundamental para que os conceitos e atitudes propagados pela Educação Ambiental possam ser aplicados no contexto do cotidiano regional". (p. 72). Como resultado do estudo é evidenciado que o rádio é um meio de comunicação de fácil acesso e atraente para a maioria dos participantes, promovendo educação pela disseminação de informações sobre questões envolvendo o turismo e o meio ambiente. Nesse sentido, é visível a responsabilidade e a potencialidade da mídia, em especial do rádio (meio de comunicação do estudo), na divulgação de conceitos de Educação Ambiental e de informações sobre turismo e meio ambiente.

A pesquisa de Bueno (2006) apresenta "As relações entre ecoturismo e Educação Ambiental no Polo de Ecoturismo da Ilha de Santa Catarina (Peisc)". O objetivo geral do estudo foi analisar as possíveis relações existentes entre o ecoturismo e a Educação Ambiental no Peisc. $\mathrm{O}$ autor utilizou entrevista estruturada como instrumento de coleta de dados, aplicada para agentes e operadores de turismo na natureza do Peisc e para gestores ou responsáveis pelos destinos do 
ecoturismo naquele polo. Bueno destaca que há evidência de uma relação histórica entre ecoturismo e educação ambiental devido a ambas serem fruto do movimento ambientalista. Também o fato de o ecoturismo ser um meio de desenvolvimento da Educação Ambiental não formal, bem como de a Educação Ambiental ser um componente e uma ferramenta do planejamento e do desenvolvimento de atividades denominadas de ecoturismo. Bueno identificou na pesquisa a existência de distintas modalidades de educação ambiental não formal (aprendizado sequencial, interpretação ambiental, educação experimental e educação no processo de gestão ambiental).

Bueno, ao questionar os sujeitos (agentes e operadores de turismo na natureza) sobre a existência do componente educativo (educação ambiental) para as atividades turísticas serem denominadas de ecoturismo, identifica nas respostas dos sujeitos o que segue: a importância do desenvolvimento de uma Educação Ambiental de lazer (recreacional); ideia de que o ecoturismo trabalha a Educação Ambiental de maneira formal; a importância de um guia para passar as informações sobre o local visitado; entendimento de que conhecer o ambiente em que será desenvolvida a atividade ecoturística seria um processo de Educação Ambiental.

Ainda Bueno, faz mais um questionamento aos mesmos sujeitos perguntando se concordam com ou discordam da frase: "A educação ambiental pode ser uma ferramenta do ecoturismo para a conservação da natureza, mas pouco se sabe sobre quais e como são desenvolvidas as modalidades (metodologias) de educação ambiental nessa atividade." Bueno constatou, através da análise dos discursos dos sujeitos, que há a possibilidade de a Educação Ambiental ser, além de um componente, uma ferramenta para o planejamento do ecoturismo para a conservação da natureza, assim como o ecoturismo pode ser utilizado para desenvolver a Educação Ambiental. Obteve também a resposta que é difícil trabalhar com ações educativas em atividades turísticas, e que ainda existe desconhecimento de metodologias para serem aplicadas em ações educativas no ecoturismo.

Bueno (2006) conclui que existe um distanciamento entre as áreas de ecoturismo e Educação Ambiental nas respostas dos sujeitos envolvidos direta e indiretamente nos processos de planejamento e desenvolvimento do ecoturismo naquele Polo.

A dissertação de Pertille (2007): "O uso turístico dos reservatórios de hidrelétricas: estudo dos terminais turísticos no Lago de Itaipu, Paraná, Brasil", buscou investigar o Turismo em reservatórios de hidrelétricas, com um estudo de caso na margem brasileira do Lago de Itaipu, localizada na Região Oeste do Estado do Paraná. Utilizou-se de questionário como instrumento de coleta de dados respondido pela direção da Itaipu Binacional e pelos responsáveis pelo projeto. Objetivou identificar as atividades turísticas e avaliar a qualidade ambiental dos terminais turísticos do Lago de Itaipu, por meio de uma avaliação simplificada de impactos ambientais. Fazem parte desses terminais turísticos: O Terminal Turístico Três Lagoas, Foz do Iguaçu; o Terminal Turístico Alvorada de Itaipu - Santa Terezinha de Itaipu; o Terminal Turístico Vila Natal Missal; o Terminal Turístico Jacutinga Itaipulândia; o Balneário de Ipiranga - São Miguel do Iguaçu; 
o Parque de Lazer e Turismo Nei Braga - Santa Helena; Parque de Lazer Entre Rios do Oeste e o Parque de Lazer Annita Wanderer - Marechal Cândido Rondon.

Também Pertille, destaca a preocupação com a Educação Ambiental no instrumento de coleta de dados, no quesito estado de conservação do atrativo e aspectos ambientais do entorno, com uma pergunta aos sujeitos relacionada à existência de um programa de Educação Ambiental para visitantes. A mesma obteve, como resposta dos sujeitos, que dos oito terminais turísticos do Lago de Itaipu pesquisados, apenas o Parque de Lazer Entre Rios do Oeste apresenta a existência de programa de Educação Ambiental para visitantes. Esse programa é identificado como "Recicla" e está relacionado à coleta seletiva de resíduos sólidos. De acordo com o estudo no momento de ingresso no terminal, os visitantes recebiam o fôlder do programa, sacos de acondicionamento de resíduos e orientações gerais junto com o regulamento do terminal.

A preocupação com a Educação Ambiental é observada também nos resultados da pesquisa em que Pertille (2007) identifica que as principais carências e ausências encontram-se na falta de controle e informações sobre capacidade de carga do Lago, refletindo na Educação Ambiental ineficiente e inexistência de controle de visitantes do lago.

Ao estudar "A variável ambiental no planejamento de eventos turísticos: estudo de caso da Festa Nacional da Uva" - RS, Pereira (2007) teve como objetivo identificar se a variável ambiental é considerada no planejamento do evento. Os objetivos específicos apresentados na pesquisa foram: verificar as relações estabelecidas entre a informação ambiental e o planejamento; identificar ações de educação ambiental no planejamento do evento; verificar a consideração do critério ambiental na escolha dos patrocinadores e expositores do evento. Pereira (2007) utilizou como instrumento de coleta de dado, um roteiro de entrevistas e também observação direta no local do evento. As entrevistas foram realizadas com gestores (presidente, vice-presidente e diretores de comissões organizadoras).

Dados importantes a serem analisados são obtidos da entrevista com os sujeitos da pesquisa sobre práticas ambientais no evento. Os sujeitos da pesquisa, ao serem questionados sobre a previsão de alguns programas de Educação Ambiental no planejamento da Festa, considerado no planejamento do evento a elaboração de algum programa de Educação Ambiental para os colabores do evento, $42,1 \%$ dos sujeitos responderam que houve planejamento de programas de Educação Ambiental para colaboradores, enquanto 31,6\% responderam não ter sido planejado e $26,3 \%$ nunca pensaram no assunto. Questionados sobre o planejamento de programa de Educação Ambiental voltado aos visitantes do evento, 52,6\% dos sujeitos responderam que foi planejado programa de Educação Ambiental para visitantes, enquanto 26,3\% responderam não ter pensado no assunto, 15,8\% responderam que não foi planejado e 5,3\% não opinaram.

Ao fazer observações diretas no local do evento, a autora obteve resultados que permitiram concluir que existiam ações ambientais implantadas de forma isolada no evento estudado. A autora constatou na pesquisa que ainda existem relações que precisam ser estabelecidas entre a variável ambiental e o planejamento de eventos turísticos. 
Das recomendações feitas pela autora para o evento estudado, destaca-se a inserção da Educação Ambiental nos desfiles temáticos da festa.

No que tange ao ecoturismo, Machado (2011) desenvolveu o estudo "Práticas ambientais na seleção, no planejamento e na comercialização do ecoturismo: informações de agências de ecoturismo do Rio Grande do Sul". O objeto de estudo de Machado foram as agências de viagens, sendo o objetivo principal: examinar as relações que se estabelecem entre as informações que os gestores de agências de viagem têm sobre o ecoturismo, e as práticas ambientais previstas na seleção, no planejamento e na comercialização de pacotes ecoturísticos. Utilizou-se de questionário (instrumento de coleta de dados) aplicado aos gestores de agências de turismo e também a observação direta nos destinos visitados: Cambará do Sul, Canela e Mostardas.

Machado (2011), ao analisar a Educação Ambiental como critério de seleção dos destinos turísticos comercializados por agências de viagem, faz o seguinte questionamento: 0 desenvolvimento de programas ou práticas de Educação Ambiental é um critério para seleção do destino turístico a ser comercializado? O autor verificou, por meio desse questionamento, que $55 \%$ dos sujeitos (gestores de agências de viagem) indicaram que a Educação Ambiental é um dos critérios para selecionar os destinos a serem comercializados, enquanto $40 \%$ indicaram não ser esse um dos critérios para a escolha do destino a ser comercializado. 0 autor coloca como importante a indicação de $5 \%$ dos sujeitos que responderam nunca terem pensado no assunto, uma vez que a Educação Ambiental é um dos principais princípios na composição do ecoturismo como segmento sustentável.

Ainda Machado questiona, a partir desse resultado, qual seria o entendimento dos agentes de viagem de ecoturismo sobre programas ou práticas de Educação Ambiental, uma vez que a Educação Ambiental é uma ferramenta intrínseca ao conceito de ecoturismo, ou seja, a seleção dos destinos estaria vinculada à existência de programas ou práticas de Educação Ambiental.

No momento em que houve a observação direta do autor nos destinos de ecoturismo selecionados, o mesmo demonstra a preocupação com a existência de programas de Educação Ambiental nos destinos visitados. Em um dos parques existe um programa voltado para a comunidade; no outro parque o programa de Educação Ambiental foi suspenso e estava sendo providenciada outra forma de oferecer Educação Ambiental aos visitantes e, no terceiro destino, o programa de educação ambiental também foi suspenso.

Machado (2011) concluiu que, em geral, as práticas ambientais não são consideradas critérios de seleção dos destinos de ecoturismo e que as mesmas não estão presentes, em sua totalidade, na formatação e comercialização dos pacotes de ecoturismo. Machado propõe a construção de novos conceitos para seleção, planejamento e comercialização, nos quais as práticas ambientais sejam contempladas de forma efetiva incluindo a Educação Ambiental como uma prática contínua e permanente a ser observada pelas agências de viagens. 


\section{CONSIDERAÇÕES FINAIS}

Existe uma estreita relação entre a Educação Ambiental e o Turismo: ambos transitam entre diversas áreas do conhecimento. O Turismo por ter na sua essência a ocupação de espaços e a utilização de recursos naturais nos locais visitados, carrega junto a responsabilidade de inserir a Educação Ambiental para visitantes e visitados. Os impactos ambientais da atividade turística passaram a ser observados pela sociedade (visitantes e visitados) nas últimas décadas. Pensando em sustentabilidade para a atividade turística, torna-se essencial inserir ações e práticas ambientais de forma permanente, trazendo para discussão a responsabilidade coletiva tanto do setor público, da iniciativa privada e da sociedade em geral.

Neste estudo, a análise dos dados revelou que há lacunas no que tange à produção de trabalhos sobre a temática Educação Ambiental, destacando-se que dos seis Programas de PósGraduação Stricto Sensu em Turismo no Brasil (período de 1997 a 2011), em apenas dois programas foram localizadas dissertações em que a Educação Ambiental foi alvo de investigação.

Percebe-se como tendência relacionada a regiões do país, que são estudos realizados na Região Sul do País destacando-se o Estado do Rio Grande do Sul, de Santa Catarina e do Paraná que apresentam produção em Educação Ambiental no período pesquisado.

No período estudado (1997 - 2011), das cinco dissertações identificadas como sendo em EA, destacam-se os anos de 2002 e 2006 na Univali e os anos de 2007 e 2011 na Universidade de Caxias do Sul. O estudo evidenciou que as categorias temáticas desses trabalhos dizem respeito a comunicação, ecoturismo, ecoturismo/agências de viagem, eventos e terminal turístico em reservatório de hidrelétrica.

Mesmo que de forma preliminar, a partir desse estudo destaca-se o importante papel dos Programas de Pós-Graduação Stricto Sensu em Turismo, de estimular o ensino (disciplinas) $e$ pesquisas na área da Educação Ambiental, contribuindo com a formação de mestres, doutores $e$ educadores com uma visão sistêmica sobre a sustentabilidade planetária. Desta maneira, torna-se primordial a inserção da Educação Ambiental de forma transdisciplinar na área do Turismo, que é essencialmente uma atividade de ocupação de espaços, lugares, regiões, paisagens e deve ter como preocupação a responsabilidade quanto ao uso dos recursos naturais dos locais visitados.

Com o propósito de maior compreensão e aprofundamento sobre o tema, sugere-se o desenvolvimento de novas pesquisas, no sentido de identificar as linhas de pesquisa, as disciplinas, os projetos de pesquisa e a orientação sobre a Educação Ambiental nos Programas de Pós-Graduação Stricto Sensu em Turismo no Brasil, e avaliar as relações que se estabelecem entre as mesmas. Também enseja o desenvolvimento de estudos que permitam comparar a Educação Ambiental nacional com a de outros países, importante para um mapeamento global. Sugere-se a utilização das pesquisas do tipo "estado da arte", pois as mesmas evidenciam tendências, lacunas e possibilitam discussões metodológicas, contribuindo no processo de evolução da ciência e da investigação científica, nos Programas de Pós-Graduação Stricto Sensu em Turismo. 
Sendo assim, é imprescindível que as Instituições de Ensino Superior busquem elaborar e implementar ações concretas em Educação Ambiental em seus Programas de Pós-Graduação Stricto Sensu, contribuindo para atingir os princípios e objetivos determinados pela Política Nacional de Educação Ambiental.

\section{REFERÊNCIAS}

Botelho, D. M. (2007). A Educação Ambiental como perspectiva para uma outra viagem turística: revisitando os passos do guia - educador com viajantes na Costa Doce/RS. Dissertação. Programa de PósGraduação em Educação Ambiental. Fundação Universidade Federal do Rio Grande - FURG. Disponível em: <http://www.argo.furg.br/bdtd/0000010248.pdf>. Acessado em 20 set. 2013.

Brasil. Lei 9.795, de 27 de abril de 1999. (1999). Dispõe sobre a educação ambiental, institui a Política Nacional de Educação Ambiental e dá outras providências. Disponível em:<http://www.planalto.gov.br/ccivil_03/Leis/L9795.htm>. Acessado em 04 jan. 2012.

Bueno, F. P. (2006). As relações entre ecoturismo e educação ambiental no pólo de ecoturismo da llha de Santa Catarina. Dissertação (Mestrado em Turismo e Hotelaria). Programa de Pós-Graduação em Turismo e Hotelária. Universidade do Vale do Itajaí. Centro de Educação Balneário Camboriú, Santa Catarina. Disponível em: <http://siaibib01.univali.br/pdf/Fernando\%20Protti\%20Bueno.pdf>. Acessado em 09 out. 2012.

CAPES - Coordenação de Aperfeiçoamento de Pessoal de Nível Superior. (2012a). Disponível em: <www.capes.gov.br>. Acessado em 21 mar. 2012.

. (2012b).Disponível em:

$<$ http://conteudoweb.capes.gov.br/conteudoweb/ProjetoRelacaoCursosServlet?acao=pesquisarles\&codigoA rea $=61300004 \& d e s c r i c a 0 A r e a=C I \% C A N C I A S+S O C I A I S+A P L I C A D A S+\& d e s c r i c a o A r e a C o n h e c i m e n t o=T U R$ ISMO\&descricaoAreaAvaliacao=ADMINISTRA $\% \mathrm{C} 7 \% \mathrm{C} 3 \mathrm{O} \% 2 \mathrm{C}+\mathrm{Cl} \% \mathrm{CANCIAS}+\mathrm{CONT} \% \mathrm{C} 1 \mathrm{BEIS}+\mathrm{E}+\mathrm{TURIS}$ MO>. Acessado em 21 mar. 2012.

Carvalho. L. M., Tomazello, M. G. C. \& Oliveira. H.T. (2009). Pesquisa em educação ambiental: panorama da produção brasileira e alguns de seus dilemas. Cad. CEDES. 29(77),Campinas jan./abr.2009. SciELO. pp. 1327. Disponível em: $<$ http://www.scielo.br/scielo.php?script=sci arttext\&pid=S0101$\underline{32622009000100002 \& \operatorname{lng}=e n \& n r m=i s o>}$. Acessado em 13 maio 2012.

Corrêa, L. L. (2002). Proposta Metodológica para Comunicação em Rádio - Suporte para um turismo sustentável. Dissertação (Mestrado em Turismo e Hotelaria). Programa de Pós graduação em Turismo e Hotelária. Universidade do Vale do Itajaí. Centro de Educação Superior de Balneário Camboriú, Santa Catarina.

Denicol, Maria Salete Goulart Martins (2013). A educação ambiental como objeto de estudos nos programas stricto sensu em turismo no Brasil (período 1997-2011). Dissertação (Mestrado em Turismo) Universidade de Caxias do Sul, Programa de Pós-Graduação em Turismo, Caxias do Sul - Rs.

Denicol, M. S. G. M., De Conto, S. M. \& Kunz, J. G. (2012). A Educação ambiental como objeto de estudo no seminário de pesquisa em turismo do Mercosul - SeminTur. Anais do 7o Seminário de Pesquisa em Turismo do Mercosul, Caxias do Sul: UCS, 2012. Disponível em: CD-ROM. 
Ferreira, N. S. de A. (2002). As Pesquisas denominadas "estado da arte". Educação \& Sociedade, n. 79, ano XXIII, agosto, pp. 257-272. Disponível em: <http://www.scielo.br/pdf/es/v23n79/10857.pdf>. Acessado em 08. fev. 2012.

Gil, A. C. (2011). Como elaborar projetos de pesquisa. 5. ed. São Paulo: Atlas.

Hall, C. M. \& Pedrazzinl T. (1989). Australian higher degree theses in tourism, recreation and related subjects. Lismore: Australian Institute for Tourism Industry Management. Disponível em:

<http://trove.nla.gov.au/work/16500410?q\&versionld=19366729>. Acessado em 16 ago. 2013.

Inep. Instituto Nacional de Estudos e Pesquisas Educacionais Anísio Teixeira. (2012). Instrumento de avaliação de cursos de graduação presencial e a distância. Disponível em:

<http://download.inep.gov.br/educacao_superior/avaliacao_cursos_graduacao/instrumentos/2012/instru mento_com_alteracoes_maio_12.pdf>. Acessado em 15 set. 2013.

Jafari, J. \& Aaser, D. (1988). Tourism as the subject of doctoral dissertations. Annals of Tourism Research, v. 15, pp. 407-429.

Köche, J. C. (2011). Fundamentos de metodologia científica: Teoria da ciência e iniciação à pesquisa. 29. ed. Petrópolis, RJ: Vozes.

Lorenzetti, L. \& Delizoicov, D. (2007). A produção acadêmica brasileira em educação ambiental. Disponível em: <http://www.reseau-amerique-latine.fr/ceisal-bruxelles/CyT-MA/CyT-MA-2-Lorenzetti.pdf >. Acessado em 13 fev. 2012.

Machado, A. L. de M. (2011). Práticas ambientais na seleção, no planejamento e na comercialização do ecoturismo: informações de agências de ecoturismo do Rio Grande do Sul. Dissertação de (Mestrado em Turismo)-Programa de Pós-Graduação em Turismo, Universidade de Caxias do Sul-RS. Disponível em: $<$ http://www.ucs.br/ucs/tpIPOSTurismo/posgraduacao/strictosensu/turismo/dissertacoes/apresenta cao/dissertacao alvaro.pdf >. Acessado em 24 mar. 2012.

Meyer-arendt, K. J. \& Justice, C. (2002). Tourism as the Subject of North American Doctoral Dissertations, 1987-2000. Annals of Tourism Research, 29(4), pp. 1171-1174.

Oliveira, D. E. R. \& Rezende, V. A. (2010). A pesquisa em educação ambiental no contexto da pesquisa educacional no Brasil: Tendências e perspectivas. In: Colóquio Internacional Educação e Contemporaneidade, 4, 2010, Laranjeiras - SE. Anais... Laranjeiras.

Oliveira, M. A. S., Souza, M. J. B. \& Escobar, M. A. R. (2012). A responsabilidade socioambiental (RS) nos periódicos científicos de turismo no Brasil: uma análise bibliométrica de 2001 a 2011. Anais do 70 Seminário de Pesquisa em Turismo do Mercosul, Caxias do Sul: UCS, 2012. Disponível em: CD-ROM.

Pereira, G. S. (2007). A variável ambiental no planejamento de eventos turísticos: estudo de caso da Festa Nacional da Uva - RS. Dissertação (Mestrado em Turismo) - Programa de Pós-Graduação em Turismo, Universidade de Caxias do Sul, Caxias do Sul-RS, 2007. Disponível em:

$<$ http://tede.ucs.br/tde arquivos/3/TDE-2007-07-

16T111521Z115/Publico/Dissertacao\%20Gisele\%20Silva\%20Pereira.pdf>. Acessado em 24 mar. 2012. 
Pertille, I. (2007). O uso turístico dos reservatórios de hidrelétricas: estudo dos terminais turísticos no Lago Itaipu, Paraná, Brasil. Dissertação (Mestrado em Turismo) - Programa de pós-graduação em turismo, Universidade de Caxias do Sul, Caxias do Sul-RS.

Ruschmann, D. (2001). Turismo e planejamento sustentável. A proteção do meio ambiente. (8ª. ed). Campinas-SP: Papirus.

Santos, A. M. (2004). Avaliação da qualidade da paisagem e dos atrativos turísticos do Parque Spitzkopf? Blumenau (SC). Dissertação (Mestrado em Turismo e Hotelaria). Programa de Pós graduação em Turismo e Hotelária. Universidade do Vale do Itajaí. Centro de Educação Superior de Balneário Camboriú, Santa Catarina - SC.

Sato, M. \& Santos, J. E. dos. (2003). Tendências nas Pesquisas em Educação ambiental. In: NOAL, F. O. ; ARCELOS, V. H. L. (Org). Educação Ambiental e Cidadania. Santa Cruz do Sul, RS: Edunisc, 2003. pp. 248-278.

Sauvé, L. (2005). Uma cartografia das correntes em educação ambiental. Brasil. In: Sato, M \& Carvalho, I. (Org.). Educação ambiental - Pesquisa e desafios. Porto Alegre-RS Artmed. Reimpressão 2008. pp. 17 -44.

Silva, R. do N. (2007). Ações ambientais em meios de hospedagem da região uva e vinho da serra gaúchaRS. 2007. Dissertação (Mestrado em turismo) - Programa de pós-graduação em turismo, Universidade de Caxias do Sul Caxias do Sul-RS.

Soares, M. (2002). Análise do Potencial Turístico das aves como alternativa para o desenvolvimento do turismo em bases sustentáveis no eixo Piçarras - Balneário Camboriú, do litoral Centro-Norte de Santa Catarina. Dissertação (Mestrado em Turismo e Hotelaria). Programa de Pós graduação em Turismo e Hotelária. Universidade do Vale do Itajaí. Centro de Educação Superior de Balneário Camboriú, Santa Catarina - SC.

Soares, M. B; Maciel F. (2000). Série Estado do Conhecimento no Alfabetização. Brasília. MEC/Inep/Comped2000. Disponível: em:

<http://pt.scribd.com/doc/7320587/Alfabetizacao-Magda--Livro>. Acessado em 11 fev. 2012.

Souza, D. C. de. (2010). Cartografia da Educação Ambiental nas pós-graduações Stricto Sensu Brasileiras (2003-2007): ênfase na pesquisa das áreas de Educação e de Ensino de Ciências sobre formação de professores. Dissertação (Mestrado em Ensino de Ciências e Educação Matemática), Londrina - PR.

Souza, D. C. \& Salvi, R. F. (2011). Um mapeamento da pesquisa em Educação Ambiental nas pós-graduações Stricto Sensu no Brasil (2003-2007). Revista Eletrônica do Mestrado em Educação Ambiental, Rio Grande (RS), v. 26, pp. 322-337, janeiro a junho de 2011. FURG. Rio Grande. Disponível em: <http://www.remea.furg.br/edicoes/vol26/art24v26.pdf>. Acessado em 13 jan. 2012.

Tomazello, M. G. C. (2005). Reflexões acerca das dissertações e teses brasileiras em educação ambiental do período de 1987-2001. Enseñanza de las ciências. Disponível em: $<$ http://ddd.uab.cat/pub/edlc/edlc a2005nEXTRA/edlc a2005nEXTRAp288reface.pdf $>$. Acessado em 13 fev. 2012.

Watanabe, A. A. (2008). Análise da Satisfação dos Visitantes do Parque Estadual do Rio da Onça/PR, no Contexto do Turismo em Unidades de Conservação. Dissertação (Mestrado em Turismo e Hotelaria). 
Programa de Pós graduação em Turismo e Hotelária. Universidade do Vale do Itajaí. Centro de Educação Balneário Camboriú, Santa Catarina - SC. Disponível em:

<http://siaibib01.univali.br/pdf/Andressa\%20Alves\%20Watanabe.pdf>. Acessado em 21 jan. 2013.

Weiler, B., Moyle, B. D. \& McLennan, C. (2012). Disciplines that influence tourism doctoral research the United States, Canada, Australia and New Zealand. Annals of Tourism Research, 39(3), pp. 1425-1445.

Zanette, F. G. C. (2010). Procedimento operacional padrão de governança e sustentabilidade em hotelaria. 103 f. Dissertação de (Mestrado em Turismo) - Programa de Pós-Graduação em Turismo. Universidade de Caxias do Sul - RS. Disponível em: <http://tede.ucs.br/tde arquivos/3/TDE-2011-0121T132134Z428/Publico/Dissertacao\%20Fernanda\%20G\%20C\%20Zanette.pdf>. Acessado em 02 jan. $\underline{2013}$.

Zsóka, A., Marjainé, Z., Széchy, A. \& Kocsis, T. (2013). Greening due to environmental education? Environmental knowledge, attitudes, consumer behavior and everyday pro-environmental activities of Hungarian high school and university students. Journal of Cleaner Production, n. 48, pp. 126-138. Disponível em:

<http://www.sciencedirect.com/science/article/pii/S0959652613006136>. Acessado em 29 jul. 2013.

Artigo recebido em: $14 / 06 / 2014$. Artigo aprovado em: 202/11/2014. 